\title{
Weight Loss Can Lead to Resolution of Gastroesophageal Reflux Disease Symptoms: A Prospective Intervention Trial
}

\author{
Mandeep Singh ${ }^{1,2}$, Jaehoon Lee ${ }^{3}$, Neil Gupta ${ }^{1,2}$, Srinivas Gaddam ${ }^{1}$, Bryan K. Smith ${ }^{3,4}$, \\ Sachin B. Wani ${ }^{1,2}$, Debra K. Sullivan ${ }^{4}$, Amit Rastogi ${ }^{1,2}$, Ajay Bansal ${ }^{1,2}$, Joseph E. \\ Donnelly $^{5}$, and Prateek Sharma ${ }^{1,2}$ \\ ${ }^{1}$ Department of Gastroenterology, Veterans Affairs Medical Center, Kansas City, Missouri, USA \\ 2 Department of Gastroenterology, University of Kansas Medical Center, Kansas City, Kansas, \\ USA \\ ${ }^{3}$ Center for Research Methods and Data Analysis, The University of Kansas, Lawrence, Kansas, \\ USA \\ ${ }^{4}$ Department of Dietetics and Nutrition, University of Kansas Medical Center, Kansas City, \\ Kansas, USA \\ ${ }^{5}$ Department of Energy Balance Laboratory, Center for Physical Activity and Weight \\ Management, University of Kansas Medical Center, Lawrence, Kansas, USA.
}

\begin{abstract}
Objective-Weight gain is an important risk factor for gastroesophageal reflux disease (GERD); however, whether weight loss can lead to resolution of GERD symptoms is not clear. Our aim was to measure the impact of weight loss on GERD symptoms.
\end{abstract}

Design and Methods-In a prospective cohort study at a tertiary referral center, overweight/ obese subjects (BMI 25-39.9 kg/m2) were enrolled in a structured weight loss program. Weight loss strategies included dietary modifications, increased physical activity and behavioral changes. At baseline and at 6 months, BMI and waist circumference were measured and all participants completed a validated reflux disease questionnaire.

Results-A total of 332 adult subjects, mean age 46 years and $66 \%$ women were prospectively enrolled. At baseline, the mean body weight, BMI, and waist circumference were $101( \pm 18) \mathrm{kg}, 35$ $( \pm 5) \mathrm{kg} / \mathrm{m} 2$ and $103( \pm 13) \mathrm{cm}$. At 6 months, majority of the subjects $(97 \%)$ lost weight (average weight loss: $13 \pm 7.7 \mathrm{~kg}$ ) and as compared with baseline, there was a significant decrease in the overall prevalence of GERD ( 15 vs. $37 \% ; P<0.01)$ and the mean GERD symptom score ( 1.8 vs. $5.5 ; P<0.01)$. Overall, $81 \%$ of the subjects had reduction in GERD symptom scores; $65 \%$ had complete resolution and $15 \%$ had partial resolution of reflux symptoms. There was a significant correlation between $\%$ body weight loss and reduction in GERD symptom scores $(r=0.17, P<$ $0.05)$.

Conclusions-In conclusion, the overall prevalence of GERD symptoms is high (37\%) in overweight and obese subjects. A structured weight loss program can lead to complete resolution of GERD symptoms in the majority of these subjects. 


\section{Introduction}

Over the past two decades, the prevalence of gastroesophageal reflux disease (GERD) has increased in the western population with the overall prevalence in the general population ranging from 10 to $20 \%$ (1-3). The exact etiology for the rising prevalence of GERD is not clear. Although there are no gender or racial predispositions for GERD development $(4,5)$, various lifestyle factors including increased consumption of dietary fats, smoking, and alcohol and change in BMI are potential risk factors that can lead to GERD (6-10). Several studies have suggested that weight gain and/or obesity can play a major role in the development of GERD (9-17) through mechanical changes in the gastroesophageal junction and/or altered metabolic milieu from visceral fat (lower adiponectin and increase in interleukin- $1 \beta$, tumor necrosis factor- $\alpha$ ) (18).

Over the past few decades, the prevalence of obesity in the United States has more than doubled. Recent results from the 2007-2008 National Health and Nutrition Examination Survey (NHANES), using measured height and body weight, indicated that an estimated $68 \%$ of US adults were overweight (BMI $>25 \mathrm{~kg} / \mathrm{m}^{2}$ ) and of those, $34 \%$ were obese (19). It seems intuitive that the worsening obesity epidemic and the rising prevalence of GERD symptoms may point to a cause and effect relationship. In addition, there also appears to be a dose-response relationship between increasing BMI and occurrence of GERD and related complications like erosive esophagitis $(9,16)$, Barrett's esophagus (fourfold) (20) and esophageal adenocarcinoma (16) as compared with normal weight individuals (BMI $<25$ $\left.\mathrm{kg} / \mathrm{m}^{2}\right)$.

Considering the dose-response relationship between obesity and occurrence of GERD and/ or its complications, an inverse relationship between weight loss and GERD symptoms would be expected. Previous data on the impact of weight loss achieved through various lifestyle (dietary changes and physical activity) (21-25) or surgical methods (Roux-en-Y gastric bypass or vertical band gastroplasty) (26-30) on GERD symptoms are scarce and with conflicting results (31). A systematic review evaluating the effects of various life style changes on GERD symptoms suggested that weight loss and head of bed elevation could improve symptoms of GERD (32). However, the impact of a structured weight loss program on GERD symptoms in overweight and obese subjects has not been prospectively evaluated. The aims of the current study were to assess (i) the prevalence of GERD symptoms in overweight and obese subjects and (ii) impact of weight loss on GERD symptoms.

\section{Methods}

\section{Study details}

Obese and overweight subjects were prospectively enrolled at the University of Kansas Medical Center to test the effectiveness of phone based vs. traditional face-to-face clinic program for weight loss and weight maintenance. After enrollment, participants were randomized to a weight management program, delivered either by a group conference phone call or by a traditional face-to-face clinic group. The initial 6 months of the program were aimed at $\geq 10 \%$ body weight loss from baseline and the subsequent 12 months were targeted at body weight maintenance. The study was approved by the local institutional review board.

The inclusion and exclusion criteria for participating in this structured weight loss program were:

Inclusion criteria-(i) Age 18-65 years, (ii) BMI of $25-39.9 \mathrm{~kg} / \mathrm{m}^{2}$, and (iii) subjects who were cleared for participation by their primary care physicians. 
Exclusion criteria-(i) subjects who had participated in another weight loss research project during the previous 6 months, (ii) weight loss of $>5 \%$ of body weight within previous 12 months, (iii) women pregnant during the previous 6 months, lactating, or planning pregnancy within 18 months, (iv) serious medical risks such as uncontrolled diabetes or hypertension, recent cardiac event (i.e., heart attack, angioplasty, and arrhythmia) or cancer, (vi) eating disorders such as anorexia nervosa or bulimia, (vii) serious psychiatric disorder, (viii) adherence to specialized diet regimes, e.g., multiple food allergies, vegetarian, macrobiotic, etc., (ix) lack of access to grocery store or inability to prepare a meal (i.e., military and college student), (x) severe arthritis or other reasons for restricted mobility, and (xi) BMI >39.9.

\section{Participant enrollment}

Subjects from the general population were recruited through newspaper advertising, email messages, public service messages, media contacts, and word of mouth. Interested individuals had a brief phone screen to determine their eligibility for participation in the study. All subjects enrolled in the study were required to submit a medical clearance certificate from their primary care physicians.

All participants had their demographic information, presence of comorbidities, smoking and alcohol history, use of acid suppressive medications including proton pump inhibitor (PPIs) and histamine receptor 2 antagonist, BMI $\left(\mathrm{kg} / \mathrm{m}^{2}\right)$, and waist circumference recorded at baseline and during follow-up visits. The following definitions for BMI were used; BMI $<25$ normal weight, BMI 25-29.9 as overweight, BMI $\geq 30-34.9$ as obese and BMI $\geq 35$ as severely obese. For men, a waist circumference of $\geq 102 \mathrm{~cm}$ and for women waist circumference $\geq 88 \mathrm{~cm}$ was considered abnormal.

\section{Weight loss program}

The participants were stratified by gender to the weight management program delivered by a group conference phone call or by a traditional face-to-face clinic group with an overall enrollment of $\sim 50 \%$ male and $50 \%$ female in each group.

\section{Strategies for losing weight}

At the beginning of the weight management program, all participants received a comprehensive notebook that included instructions on weight loss and maintenance, various diets, exercise protocol, calendars, and instruction on timelines for class meetings. The target body weight reduction was $10 \%$ of baseline weight at 6 months.

Dietary modifications-To achieve target weight loss, participants were instructed to reduce their total calorie intake to 1,200-1,500 cal/day using commercially available prepackaged meals, combined with fruits, vegetables, and beverages. Participants were asked to consume a minimum of three shakes at $\sim 100 \mathrm{kcal}$ each, two entrees between 200 and $270 \mathrm{kcal}$ each, and five fruits or vegetables per day.

Physical activity-Self-directed instructions were provided to all participants to undergo moderately vigorous home-based physical activity of walking/other exercise of 15-60 min/ day up to 5 days per week. The exercise progression started at $45 \mathrm{~min} /$ week ( 3 days/week, $15 \mathrm{~min} /$ day) and progressed to $300 \mathrm{~min} /$ week ( 5 days/week, $60 \mathrm{~min} /$ day) by week 12 .

Behavioral strategies-Several behavioral strategies including behavior shaping, goal setting, self-monitoring, feedback and reinforcement, social support, problem solving, and relapse prevention were conducted by in-class discussions and activities and regular out-of- 
class assignments to help participants modify their lifestyles for achieving targeted weight loss.

\section{Follow-up meetings}

Group meetings of 60 min duration were held weekly during the initial 6 months. During these group meetings, the initial $10 \mathrm{~min}$ were devoted to weight measurements, calculations on physical activity, and assessment of compliance to dietary protocol including number of fruits and vegetables and prepackaged meals consumed per week. Following this, a 30-min lesson on behavioral modifications including nutrition, physical activity, and lifestyle modifications was presented by a health educator. The remaining 20 min consisted of group discussion, problem solving and/or assignments designed to help the participants practice and develop the behavioral strategies for successful weight loss. Similar instructions for losing weight were delivered as group conference phone calls that were identical to the traditional face-to-face group clinics and were conducted by a health educator. Participants were required to email, fax, or call in their weekly data and self-reported weights the evening before the day of class. The class schedule included check-in questions, data review (use of prepackaged meals, fruits and vegetables, physical activity etc.), lessons and problem solving, and also the assignments for the upcoming week.

\section{Diagnosis of GERD and recording of symptoms at baseline and follow-up}

All participants enrolled in this weight loss program completed a validated GERD questionnaire (reflux disease questionnaire (RDQ)) at baseline and follow-up visits. The RDQ comprises of 12 questions; six each related to reflux symptom frequency and severity and each question was assigned a score of 0-3. This questionnaire pertains to three major components-heartburn, regurgitation, and dyspepsia. Based on the response a cumulative additive score on response to all the 12 questions could range from 0 to 36 . For the current study, the score was calculated based on the responses only to heartburn and regurgitation with a score ranging from 0 to 24 . Based on previous studies using the RDQ, the presence of GERD was defined as RDQ score of $\geq 2$ with at least weekly heartburn and/or regurgitation symptoms (2). Severity rating of GERD symptoms was also based on the responses in the questionnaire: severity score of 1 was rated as mild, 2 as moderate, and 3 as severe GERD symptoms. The RDQ questionnaire has been previously validated and has scored highly on multiple criteria including internal consistency, item discrimination, test-retest reliability, and regression with specialty physician diagnosis (33). Data suggests that RDQ performs well across different populations and correlates well with treatment responses $(33,34)$.

All participants completed the RDQ at 6-month follow-up regardless of changes in body weight and waist circumference. Changes in RDQ questionnaire score were used to define changes in GERD symptoms. At 6-month follow-up, complete resolution of GERD was defined as a RDQ score of 1 or less, partial improvement in GERD as any decrease in RDQ and worsening GERD if there was any increase in the baseline RDQ score.

\section{Data collection, assessment of outcomes, and statistical analysis}

Outcome data, body weight and other physical findings were recorded in the clinic (for both phone and clinic groups) at regular intervals. Participants of both groups also reported by phone or during clinic visit the number of prepackaged meals consumed and estimated physical activity.

Descriptive statistics were calculated at baseline and follow-up. Paired $t$-test was used to compare changes in GERD symptoms scores, body weight, and waist circumference between baseline and 6-month follow-up. Presence of GERD, heartburn, and regurgitation symptoms with varying degrees of weight loss $(<5,5-10$, and $>10 \%)$, and decrease in waist 
circumference $\left(5,5-10\right.$, and $>10 \mathrm{~cm}$ ) were also compared using $\chi^{2}$ test. Pearson's correlation coefficients $(r)$ were calculated to evaluate the association between changes in overall GERD, heartburn, and regurgitation symptom scores with mean and percent body weight and waist circumference changes. A $P$ value $<0.05$ was considered significant.

Post hoc power estimates suggested that the proposed analyses were adequately powered in this study. Achieved power was $0.99-1$ and 1 for paired $t$-test and $\chi^{2}$ test, respectively. Power of 0.88 was achieved for testing the association between change in GERD symptoms score and percent body weight change. For the other associations, however, power was not satisfactory (0.15-0.59). All statistical analyses were conducted using SAS version 9.2 (SAS Institute, Cary, NC).

\section{Results}

\section{Baseline characteristics}

A total of 332 subjects were enrolled in the weight loss program and completed the RDQ at baseline and at 6-month follow-up. The mean age was 46 (range 19-66) years, $80 \%$ were Caucasians, $15 \%$ African-Americans and included $66 \%$ women. The mean weight, BMI, and waist circumference were $101( \pm 18) \mathrm{kg}, 35( \pm 5) \mathrm{kg} / \mathrm{m}^{2}$, and $103( \pm 13) \mathrm{cm}$, respectively and the vast majority had a BMI $>35(83 \%)$ and a waist circumference $>100 \mathrm{~cm}(58 \%)$ (Table 1). Eighty nine subjects (27\%) had a history of hypertension, $26(8 \%)$ had diabetes mellitus and one with heart disease.

Consecutive subjects were randomized to either the clinic based (167 subjects) or phone based (165 subjects) weight loss program and each group comprised of 41 and $33 \%$ subjects with GERD, respectively $(P=$ not significant $)$.

\section{Overall prevalence of GERD in the study population}

The baseline prevalence of GERD in this cohort was 37\% (124/332). Regurgitation ( $n=86$; $26 \%)$ was reported more frequently than heartburn $(n=61 ; 18 \%)$ with approximately a third of the symptomatic subjects $(n=36 ; 29 \%)$ experiencing moderate to severe GERD symptoms.

\section{GERD symptoms scores during follow-up}

The majority of the subjects (97\%) lost weight at the 6-month follow-up period with a mean weight loss of $13.1( \pm 7.7) \mathrm{kg}$ and a mean decrease in waist circumference by $10.6( \pm 9.1) \mathrm{cm}$. Compared with baseline, there was a significant decrease in the overall prevalence of GERD symptoms ( 15 vs. $37 \% ; P<0.01)$ with significant improvements in overall symptom, heartburn and regurgitation scores (all $P<0.01$ ). The mean reduction in GERD symptom score was $1.3( \pm 3.5)$ (Tables 1 and 2$)$. There was no significant difference in the degree of weight loss and/or GERD symptom scores between the two groups i.e., those enrolled in phone vs. clinic based weight loss programs. Among subjects who had GERD at baseline, $81 \%$ had a reduction in GERD scores $(65 \%$ with complete resolution and $15 \%$ with partial resolution), $13 \%$ had no change whereas $7 \%$ subjects had worsening of their GERD symptoms. There was no significant difference in the use of acid suppressive medications (including PPIs and histamine receptor 2 antagonists) at baseline (11\%) and during followup $(8 \%),(P=$ not significant) (Table 1$)$.

\section{Correlation between degree of weight loss and GERD scores}

A positive correlation was observed between the degree of body weight loss (percent change) and change in GERD symptom scores over the 6-month follow-up period. There was a significant improvement in overall GERD symptoms with percent body weight loss 
(Pearson's correlation coefficient, $r=0.17, P<0.05$ ) (Figure 1). Similarly, a significant association between percent body weight loss and decrease in heartburn scores was noted $(r$ $=0.12, P<0.05)$ however, the correlation between degree of body weight loss and regurgitation scores was not significant $(r=0.12, P=$ not significant). There was no significant correlation between decrease in waist circumference (mean or percent) and overall GERD, heartburn or regurgitation symptom scores; $r=0.05,0.08$, and 0.06 , respectively (all $P=$ not significant) (Figure 1).

\section{GERD symptoms and gender differences}

Subjects were then sub-grouped into different body weight reduction categories of $<5,5-10$, and $\geq 10 \%$ and decrease in waist circumference to $<5,5-10$, and $\geq 10 \mathrm{~cm}$. There was no significant change in overall GERD symptom scores with $<5 \%$ weight loss of baseline body weight for all subjects. However, a weight loss of 5-10\% lead to a significant reduction in overall GERD scores $(P<0.05)$ in women. Whereas among men, a significant improvement in GERD symptom scores $(P<0.01)$ was observed after a weight loss of $\geq 10 \%$ of baseline body weight. Similarly, there was no significant change in overall GERD symptom scores with a $<5 \mathrm{~cm}$ waist circumference reduction (from baseline waist circumference). However, losing 5-10 cm waist circumference led to a significant reduction in GERD symptoms $(P<$ $0.01)$, among women. In men, there was a significant reduction in GERD symptoms $(P<$ 0.01 ) with a waist circumference decrease of $\geq 10 \mathrm{~cm}$ (Table 3 ).

\section{Discussion}

Over the last few decades there has been steady increase in the prevalence of GERD $(1,2,3,9,35)$ and several recent studies have suggested a significant association between obesity and GERD (9-17). The prevalence of GERD has been shown to increase with increasing BMI $(9,16,20)$ and ranges from 59 to $79 \%$ among extremely obese subjects (35-37). As conservative measures for the management of GERD symptoms, although various lifestyle (including weight loss) and dietary modifications have been suggested by a variety of guidelines and consensus conferences, there is no evidence-based prospective data to support the efficacy of these measures (38). The results of our study showed that GERD symptoms were prevalent in 37\% of overweight and/or obese individuals enrolled in a weight loss program. Furthermore, results of our prospective study showed that weight loss led to a significant improvement in GERD symptoms, thus establishing weight loss as an important life style modification for the treatment of GERD. In this study cohort, weight loss over a 6-month period, the majority of subjects $(81 \%)$ experienced a reduction in GERD symptoms and $65 \%$ of the study subjects with complete resolution of reflux symptoms.

Contemporary studies evaluating the effect of weight loss in GERD subjects are lacking and ours is the largest prospective trial conducted on this topic. One Swedish study from 1999 evaluated only 34 overweight patients (BMI >23, excluding severely obese) and did show a positive correlation between weight loss and improvement of GERD symptom (21). Another study, as yet in abstract form, was exclusively conducted in obese (BMI 30-39) subjects and also showed a positive correlation between improvement in GERD symptoms with decrease in BMI as well as reductions in waist-hip ratio; odds ratios of 1.10 (95\% confidence intervals: 1-1.2) and 1.08 (95\% confidence intervals:1-1.1), respectively (35).

However, a few previous studies including severely obese subjects enrolled in a low calorie diet based weight loss protocol failed to show any significant change in GERD symptoms despite a weight loss of up to $10 \mathrm{~kg}(23,25)$ or more (24). These varied results of weight loss on GERD symptoms could be because of small sample size, gender differences, wide variation in BMI of subjects (23 vs. 43), and use of different weight loss methods (various lifestyle changes vs. surgical approaches) (21-35). Furthermore, a number of lifestyle 
intervention treatments have been attempted for GERD-low calorie diet, use of fruits/ vegetables, and physical activity; individually each intervention has no direct correlation with GERD improvement as shown in previous population-based studies $(13,22,23)$ and a recent meta-analysis (32). Previous studies have reported no change in GERD with weight loss achieved by low calorie diet alone (25) or in combination with gastric surgery (vertical band gastroplasty) (23) without increase in physical activity. These results suggest that a structured weight loss program (combination of diet, physical activity, and behavioral changes) may be necessary for impact on GERD symptoms.

Studies have shown a dose-response relationship between weight gain (BMI) and occurrence of GERD and complications of erosive esophagitis, Barrett's esophagus and esophageal adenocarcinoma $(9,13,16,20)$. A questionnaire based large cohort study of middle-aged women nurses, over a period of 25 years, demonstrated a clear dose-dependent increase in the frequency of GERD symptoms with increase in BMI. Overweight and obese women had two to three times higher chance of having GERD symptoms as compared with those with normal weight (13) suggesting a temporal association between weight change and GERD symptoms. We observed a similar association between the degree of weight loss and improvement in GERD symptoms further strengthening the concept of a direct relationship between these two variables. However, some gender differences were noted-a weight loss of 5-10\% led to a significant reduction in overall GERD scores $(P<0.05)$ in women; whereas among men, a significant improvement in GERD symptom scores $(P<0.01)$ was observed after a weight loss of $\geq 10 \%$ of baseline body weight. Similar to this concept, new onset or worsening of pre-existing GERD may occur only after certain threshold weight change as was reported in previous study by Rey et al. (39) In that study subjects who gained $>5 \mathrm{~kg}$ showed three times significantly higher frequency of new onset GERD (39). Although a positive and significant correlation between weight loss and GERD scores was noted, it appears that the correlation is not linear and more complex. The change in GERD scores among obese subjects probably occurs secondary to multiple factors such as gender, proportional changes in abdominal vs. peripheral fat weight, hormonal (adiponectin), and genetic factors besides weight loss. In the current study, not all obese subjects with GERD who lost weight had reduction in GERD scores, $13 \%$ had no change whereas $7 \%$ subjects had worsening of their GERD symptoms. Therefore, weight change is probably one of the factors that affect GERD symptoms.

Therefore, a small percentage of overweight and or obese subjects may not have resolution of GERD with weight loss; future trials defining predictors of GERD improvement in overweight/obese subjects are required. At baseline, a small number (11\%) of subjects used PPIs and this decreased to $8 \%$ at the 6-month follow-up however, the number of subjects using PPIs was small and therefore no inference can be made on whether obese subjects with GERD symptoms would need less or no medications after losing weight.

There were a few limitations to this study. The impact of weight gain on GERD occurrence could not be evaluated as the majority (97\%) of subjects lost weight at 6 months and had improvement in their reflux symptoms. Although this is a prospective longitudinal study, the treatment was not randomized and lacks a control group. Unlike most previous studies that specifically included either over-weight or severely obese populations only, we included both over-weight and obese subjects (BMI 25-39.9) but the majority were healthy and required a clearance letter from their primary care physicians for participating in the study; hence study results may not be generalized to all overweight, obese individuals. In the current study, subjects lost weight by combination of dietary, behavioral, and physical activity changes; therefore the contribution of each modality separately on GERD symptoms could not be evaluated. Finally, although, we used a validated questionnaire (RDQ) for diagnosing and monitoring GERD symptoms, endoscopy and/or pH monitoring was not 
performed. Despite these limitations, the results of this prospective study are highly suggestive of obesity as a major contributor to GERD and that weight loss can lead to resolution of GERD symptoms in the majority of overweight and/or obese subjects. The large patient population, evaluation of both men and women, use of a structured weight loss program and an objective, validated symptom questionnaire are strengths of our study. These results have significant clinical implications. Using weight loss as an important first line treatment for GERD in overweight, obese individuals could potentially result in significant cost savings on medical treatment, prevent complications of GERD, as well as improve quality of life and overall health status. These categories of over-weight and obese subjects constitutes a major part (68\%) of the US population (2008 NHANES consensus) (19) and hence these results could have wide-spread clinical implications for management of GERD. The estimates show that in excess of 10 billion US dollars a year are spent on medical therapy (PPIs) (40) thus presenting a significant economic burden on the health-care system.

In summary, $\sim 40 \%$ of adult subjects enrolled in weight loss programs that were overweight and/or obese experienced GERD symptoms. Through a structured weight loss program including dietary, physical activity and behavioral changes, the majority of these subjects achieved complete resolution of their GERD symptoms. There appeared to be a doseresponse relationship between the degree of body weight loss and resolution of GERD symptoms and the threshold weight loss for such an improvement was lower in women compared to men (5-10 vs. >10\% body weight reduction).

\section{Acknowledgments}

We thank the staff of the Weight Control Research Project at the University of Kansas, Renee Sol (Project Coordinator). Funded by NIDDK grant \# DK076063 to J.E. Donnelly for study titled "Equivalent weight loss for phone and clinic weight management programs".

\section{References}

1. El-Serag HB. Time trends of gastroesophageal reflux disease: a systematic review. Clin Gastroenterol Hepatol. 2007; 5:17-26. [PubMed: 17142109]

2. Dent J, El-Serag HB, Wallander MA, Johansson S. Epidemiology of gastro-oesophageal reflux disease: a systematic review. Gut. 2005; 54:710-717. [PubMed: 15831922]

3. Locke GR III, Talley NJ, Fett SL, Zinsmeister AR, Melton LJ III. Prevalence and clinical spectrum of gastroesophageal reflux: a population-based study in Olmsted County, Minnesota. Gastroenterology. 1997; 112:1448-1456. [PubMed: 9136821]

4. El-Serag HB, Petersen NJ, Carter J, et al. Gastroesophageal reflux among different racial groups in the United States. Gastroenterology. 2004; 126:1692-1699. [PubMed: 15188164]

5. Sharma P, Wani S, Romero Y, Johnson D, Hamilton F. Racial and geographic issues in gastroesophageal reflux disease. Am J Gastroenterol. 2008; 103:2669-2680. [PubMed: 19032462]

6. Wang JH, Luo JY, Dong L, Gong J, Tong M. Epidemiology of gastroesophageal reflux disease: a general population-based study in Xi'an of Northwest China. World J Gastroenterol. 2004; 10:1647-1651. [PubMed: 15162542]

7. Nilsson M, Johnsen R, Ye W, Hveem K, Lagergren J. Lifestyle related risk factors in the aetiology of gastro-oesophageal reflux. Gut. 2004; 53:1730-1735. [PubMed: 15542505]

8. Becker DJ, Sinclair J, Castell DO, Wu WC. A comparison of high and low fat meals on postprandial esophageal acid exposure. Am J Gastroenterol. 1989; 84:782-786. [PubMed: 2741888]

9. El-Serag HB, Graham DY, Satia JA, Rabeneck L. Obesity is an independent risk factor for GERD symptoms and erosive esophagitis. Am J Gastroenterol. 2005; 100:1243-1250. [PubMed: 15929752]

10. Corley DA, Kubo A. Body mass index and gastroesophageal reflux disease: a systematic review and meta-analysis. Am J Gastroenterol. 2006; 101:2619-2628. [PubMed: 16952280] 
11. Delgado-Aros S, Locke GR III, Camilleri M, et al. Obesity is associated with increased risk of gastrointestinal symptoms: a population-based study. Am J Gastroenterol. 2004; 99:1801-1806. [PubMed: 15330922]

12. Nilsson M, Johnsen R, Ye W, Hveem K, Lagergren J. Obesity and estrogen as risk factors for gastroesophageal reflux symptoms. JAMA. 2003; 290:66-72. [PubMed: 12837713]

13. Jacobson BC, Somers SC, Fuchs CS, Kelly CP, Camargo CA Jr. Body-mass index and symptoms of gastroesophageal reflux in women. N Engl J Med. 2006; 354:2340-2348. [PubMed: 16738270]

14. Kulig M, Nocon M, Vieth M, et al. Risk factors of gastroesophageal reflux disease: methodology and first epidemiological results of the ProGERD study. J Clin Epidemiol. 2004; 57:580-589. [PubMed: 15246126]

15. Murray L, Johnston B, Lane A, et al. Relationship between body mass and gastro-oesophageal reflux symptoms: The Bristol Helicobacter Project. Int J Epidemiol. 2003; 32:645-650. [PubMed: 12913045]

16. Hampel H, Abraham NS, El-Serag HB. Meta-analysis: obesity and the risk for gastroesophageal reflux disease and its complications. Ann Intern Med. 2005; 143:199-211. [PubMed: 16061918]

17. Locke GR 3rd, Talley NJ, Fett SL, Zinsmeister AR, Melton LJ 3rd. Risk factors associated with symptoms of gastroesophageal reflux. Am J Med. 1999; 106:642-649. [PubMed: 10378622]

18. Festi D, Scaioli E, Baldi F, et al. Body weight, lifestyle, dietary habits and gastro-esophageal reflux disease. World J Gastroenterol. 2009; 15:1690-1701. [PubMed: 19360912]

19. Flegal KM, Carroll MD, Ogden CL, Curtin LR. Prevalence and trends in obesity among US adults, 1999-2008. JAMA. 2010; 303:235-241. [PubMed: 20071471]

20. El-Serag HB, Kvapil P, Hacken-Bitar J, Kramer JR. Abdominal obesity and the risk of Barrett's esophagus. Am J Gastroenterol. 2005; 100:2151-2156. [PubMed: 16181362]

21. Fraser-Moodie CA, Norton B, Gornall C, et al. Weight loss has an independent beneficial effect on symptoms of gastro-oesophageal reflux in patients who are over-weight. Scand J Gastroenterol. 1999; 34:337-340. [PubMed: 10365891]

22. Austin GL, Thiny MT, Westman EC, Yancy WS Jr, Shaheen NJ. A very low-carbohydrate diet improves gastroesophageal reflux and its symptoms. Dig Dis Sci. 2006; 51:1307-1312. [PubMed: 16871438]

23. Frederiksen SG, Johansson J, Johnsson F, Hedenbro J. Neither low-calorie diet nor vertical banded gastroplasty influence gastro-oesophageal reflux in morbidly obese patients. Eur J Surg. 2000; 166:296-300. [PubMed: 10817325]

24. Mathus-Vliegen LM, Tytgat GN. Twenty-four-hour pH measurements in morbid obesity: effects of massive overweight, weight loss and gastric distension. Eur J Gastroenterol Hepatol. 1996; 8:635640. [PubMed: 8853250]

25. Kjellin A, Ramel S, Rössner S, Thor K. Gastroesophageal reflux in obese patients is not reduced by weight reduction. Scand J Gastroenterol. 1996; 31:1047-1051. [PubMed: 8938895]

26. Korenkov M, Köhler L, Yücel N, et al. Esophageal motility and reflux symptoms before and after bariatric surgery. Obes Surg. 2002; 12:72-76. [PubMed: 11868303]

27. Merrouche M, Sabat e JM, Jouet P, et al. Gastro-esophageal reflux and esophageal motility disorders in morbidly obese patients before and after bariatric surgery. Obes Surg. 2007; 17:894900. [PubMed: 17894148]

28. Deitel M, Khanna RK, Hagen J, Ilves R. Vertical banded gastroplasty as an antire-flux procedure. Am J Surg. 1988; 155:512-516. [PubMed: 3344920]

29. Madalosso CA, Gurski RR, Callegari-Jacques SM, et al. The impact of gastric bypass on gastroesophageal reflux disease in patients with morbid obesity: a prospective study based on the Montreal Consensus. Ann Surg. 2010; 251:244-248. [PubMed: 20010088]

30. Frezza EE, Ikramuddin S, Gourash W, et al. Symptomatic improvement in gastro-esophageal reflux disease (GERD) following laparoscopic Roux-en-Y gastric bypass. Surg Endosc. 2002; 16:1027-1031. [PubMed: 11984683]

31. De Groot NL, Burgerhart JS, Van De Meeberg PC, et al. Systematic review: the effects of conservative and surgical treatment for obesity on gastro-oesophageal reflux disease. Aliment Pharmacol Ther. 2009; 30:1091-1102. [PubMed: 19758397] 
32. Kaltenbach T, Crockett S, Gerson LB. Are lifestyle measures effective in patients with gastroesophageal reflux disease? An evidence-based approach. Arch Intern Med. 2006; 166:965971. [PubMed: 16682569]

33. Shaw MJ, Talley NJ, Beebe TJ, et al. Initial validation of a diagnostic questionnaire for gastroesophageal reflux disease. Am J Gastroenterol. 2001; 96:52-57. [PubMed: 11197287]

34. Shaw M, Dent J, Beebe T, et al. The Reflux Disease Questionnaire: a measure for assessment of treatment response in clinical trials. Health Qual Life Outcomes. 2008; 6:31. [PubMed: 18447946]

35. Crowell M, Levy RL, Dibaise JK, et al. W1075 symptomatic improvement in gastroesophageal reflux disease (GERD) following weight loss through caloric restriction and behavioral modification. Gastroenterology. 2010; 138:S-646.

36. Ortiz V, Ponce M, Fern andez A, et al. Value of heartburn for diagnosing gastro-esophageal reflux disease in severely obese patients. Obesity (Silver Spring). 2006; 14:696-700. [PubMed: 16741272]

37. Hagen J, Deitel M, Khanna RK, Ilves R. Gastroesophageal reflux in the massively obese. Int Surg. 1987; 72:1-3. [PubMed: 3596968]

38. DeVault KR, Castell DO, American College of Gastroenterology. Updated guidelines for the diagnosis and treatment of gastroesophageal reflux disease. Am J Gastroenterol. 2005; 100:190 200. [PubMed: 15654800]

39. Rey E, Moreno-Elola-Olaso C, Artalejo FR, Locke GR III, Diaz-Rubio M. Association between weight gain and symptoms of gastroesophageal reflux in the general population. Am J Gastroenterol. 2006; 101:229-233. [PubMed: 16454823]

40. Shaheen NJ, Hansen RA, Morgan DR, et al. The burden of gastrointestinal and liver diseases, 2006. Am J Gastroenterol. 2006; 101:2128-2138. [PubMed: 16848807] 

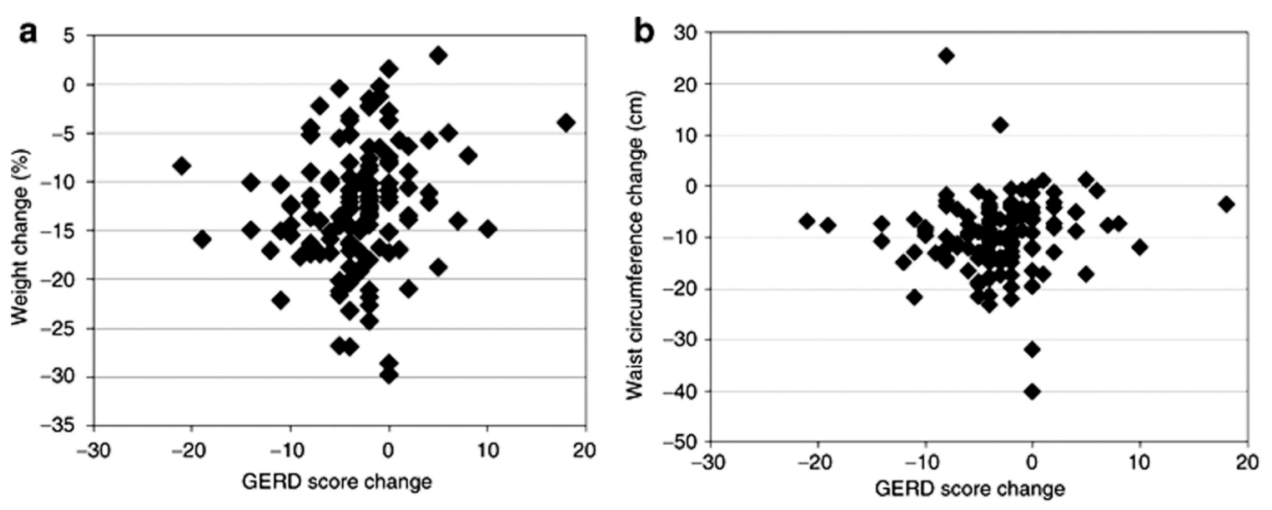

FIGURE 1.

Scatter plot diagram showing dose-response relationship between gastroesophageal reflux disease symptom scores and (a) degree of weight loss, $r=0.17, P<0.05$, and (b) reduction in waist circumference, $r=0.05, P=$ not significant. 


\section{TABLE 1}

Clinical characteristics of all subjects enrolled in a weight loss program (baseline and 6 months)

\begin{tabular}{lccc}
\hline Variable & Baseline $(\boldsymbol{N}=\mathbf{3 3 2})$ & 6-month follow-up $(\boldsymbol{N}=\mathbf{3 3 2})$ & $\boldsymbol{P}$ \\
\hline Weight $(\mathrm{kg})$ & $100.7 \pm 18.1$ & $87.6 \pm 16.7$ & $<0.01$ \\
BMI $\left(\mathrm{kg} / \mathrm{m}^{2}\right)$ & $34.7 \pm 4.6$ & $30.2 \pm 5.0$ & $<0.01$ \\
Waist circumference $(\mathrm{cm})$ & $102.7 \pm 12.9$ & $92.1 \pm 13.0$ & $<0.01$ \\
Subjects with GERD symptoms & $124(37 \%)$ & $51(15 \%)$ & $<0.01$ \\
GERD symptom score & $2.1 \pm 3.7$ & $0.8 \pm 2.6$ & $<0.01$ \\
Heartburn score & $0.6 \pm 1.4$ & $0.3 \pm 1.1$ & $<0.01$ \\
Regurgitation score & $0.9 \pm 1.6$ & $0.3 \pm 0.9$ & $<0.01$ \\
PPIs/H2RAs use & $35(11 \%)$ & $26(8 \%)$ & $\mathrm{ns}$ \\
\hline
\end{tabular}

GERD, gastroesophageal reflux disease; H2RA; histamine 2 receptor antagonist; ns, not significant; PPI, proton pump inhibitor. 
TABLE 2

Change in overall GERD symptom scores (measured by RDQ) with weight loss

\begin{tabular}{lccc}
\hline Variable & Baseline $(\boldsymbol{N}=\mathbf{1 2 4})$ & 6-month follow-up $(\boldsymbol{N}=\mathbf{1 2 4})$ & $\boldsymbol{P}$ \\
\hline Weight $(\mathrm{kg})$ & $100.5 \pm 18.6$ & $87.7 \pm 17.3$ & $<0.01$ \\
BMI & $34.7 \pm 4.4$ & $30.4 \pm 4.5$ & $<0.01$ \\
Waist circumference $(\mathrm{cm})$ & $103.4+13.3$ & $93.7 \pm 11.4$ & $<0.01$ \\
Overall GERD score & $5.5 \pm 4.3$ & $1.8 \pm 3.6$ & $<0.01$ \\
Heart burn score & $1.6 \pm 2.0$ & $0.5 \pm 1.5$ & $<0.01$ \\
Regurgitation score & $2.3 \pm 2.0$ & $0.6 \pm 1.4$ & $<0.01$ \\
\hline
\end{tabular}

GERD, gastroesophageal reflux disease; RDQ, reflux disease questionnaire. 
TABLE 3

Threshold body weight loss or waist circumference decrease for improvement in overall GERD symptom score and heartburn/regurgitation scores among men and women

\begin{tabular}{|c|c|c|c|c|c|c|c|c|}
\hline $\begin{array}{l}\text { Change in body } \\
\text { weight and waist } \\
\text { circumference }\end{array}$ & & & $\begin{array}{c}\text { Overall } \\
\text { GERD } \\
\text { symptom } \\
\text { score } \\
\text { change }\end{array}$ & $P$ & Heartburn score change & $P$ & Regurgitation score change & $P$ \\
\hline \multicolumn{9}{|l|}{ Men } \\
\hline \multirow[t]{2}{*}{$\begin{array}{l}\text { Percent body weight } \\
\text { loss }(\%)(N=105)\end{array}$} & $5-10$ & 21 & $\pm 0.2 \pm 2.3$ & 0.71 & $-0.1 \pm 0.4$ & 0.33 & $\pm 0.2 \pm 1.1$ & 0.43 \\
\hline & $\geq 10$ & 84 & $-1.7 \pm 3.7$ & $<0.01$ & $-0.5 \pm 1.4$ & $<0.01$ & $-0.7 \pm 1.6$ & $<0.01$ \\
\hline \multirow{2}{*}{$\begin{array}{l}\text { Waist circumference } \\
\text { decrease }(\mathrm{cm})(N= \\
104)\end{array}$} & $5-10$ & 25 & $-1.3 \pm 4.5$ & 0.17 & $-0.6 \pm 1.4$ & 0.06 & $-0.2 \pm 1.8$ & 0.50 \\
\hline & $\geq 10$ & 79 & $-1.5 \pm 3.2$ & $<0.01$ & $-0.4 \pm 1.3$ & $<0.01$ & $-0.7 \pm 1.5$ & $<0.01$ \\
\hline \multicolumn{9}{|l|}{ Women } \\
\hline \multirow{2}{*}{$\begin{array}{l}\text { Percent body weight } \\
\text { loss }(\%)(N=189)\end{array}$} & $5-10$ & 51 & $-1.2 \pm 3.5$ & $<0.05$ & $-0.3 \pm 1.3$ & 0.11 & $-0.7 \pm 1.6$ & $<0.01$ \\
\hline & $\geq 10$ & 138 & $-1.5 \pm 3.3$ & $<0.01$ & $-0.4 \pm 1.6$ & $<0.01$ & $-0.7 \pm 1.6$ & $<0.01$ \\
\hline \multirow{2}{*}{$\begin{array}{l}\text { Waist circumference } \\
\text { decrease }(\mathrm{cm})(N= \\
\text { 157) }\end{array}$} & $5-10$ & 79 & $-1.6 \pm 4.1$ & $<0.01$ & $-0.3 \pm 1.9$ & 0.12 & $-0.8 \pm 1.5$ & $<0.01$ \\
\hline & $\geq 10$ & 78 & $-1.1 \pm 2.6$ & $<0.01$ & $-0.4 \pm 1.2$ & $<0.05$ & $-0.5 \pm 1.6$ & $<0.01$ \\
\hline
\end{tabular}

All values represent mean \pm s.d.

GERD, gastroesophageal reflux disease. 